\title{
Spontaneous electromyographic activity throughout the cycle in the sow and its change by intrauterine oestrogen infusion during oestrus
}

\author{
R. Claus*, F. Ellendorff $\dagger \ddagger$ and C. Hoang-Vu* \\ *Universität Hohenheim, Institut für Tierhaltung und Tierzüchtung, POP 7005627000 Stuttgart \\ 70, FRG; and $\uparrow$ Institut für Tierzucht und Tierverhalten (FAL), Mariensee, 3057 Neustadt, FRG
}

\begin{abstract}
Summary. Two experiments were carried out to monitor influences on the uterine electromyographic activity (EMG) in cyclic gilts with chronic uterine EMG electrodes. In Exp. 1 the EMG was recorded continuously from Day - 1 for 24 days and was evaluated for frequency, duration and amplitude. Progesterone and oestradiol in peripheral plasma were measured daily. As high amounts of oestrogens are characteristic for boar semen, in Exp. 2 the influence of seminal oestrogens on uterine contractions at Day 0 (first day of standing reflex) was investigated in gilts with chronic intrauterine catheters. They were infused with $10 \mathrm{ml}$ saline $(\mathrm{N}=4)$ or saline with physiological amounts of oestrogens $(5 \mu \mathrm{g}$ oestradiol $+2 \mu \mathrm{g}$ oestrone $+4.5 \mu \mathrm{g}$ oestrone sulphate; $N=4$ ). Sham-treated gilts (infusion catheters, no infusion; $N=5$ ) served as controls. The EMG was recorded for $2 \mathrm{~h}$ before and $9 \mathrm{~h}$ after infusion.

In Exp. 1 the maximal amplitude $(2040 \pm 98 \mu \mathrm{V})$ and duration $(32 \pm 1.7 \mathrm{sec})$ but the lowest frequency $(15 \cdot 8 \pm 2 \cdot 1$ contractions/h) were found on Day 0 . With decreasing oestrogen and increasing progesterone concentrations the frequency increased continuously until Day $5(63.5 \pm 1.0$ contractions/h) while the amplitude $(183 \pm 13 \mu \mathrm{V})$ and duration $(3.3 \pm 0.7 \mathrm{sec})$ decreased. During Days $6-13$ the EMG activity was not detectable. The reverse pattern was found from the onset of luteolysis until the following Day 0. On Day 0 a significant correlation between oestradiol and the duration $(r=0.81 ; P<0.01 ; n=10)$ but not the frequency was observed.

In Exp. 2 no significant change in contractile activity was found for the salineinfused group and the controls over the 11-h recording periods. After infusion of saline with oestrogens the frequency increased significantly $(P<0.001)$ from $14.0 \pm 3 \cdot 1$ contractions/h during the first hour up to a maximum of $31 \cdot 2 \pm 3 \cdot 9 / \mathrm{h}$ at $2 \mathrm{~h}$ after infusion. Compared to the pretreatment period the frequency remained significantly elevated during the $3 \mathrm{rd}(28.7 \pm 2.3 / \mathrm{h} ; P<0.05)$ and 4 th $(20.2 \pm 3.9 / \mathrm{h} ; P<0.05)$ hour after infusion. Seminal oestrogens therefore stimulate uterine contractions at Day 0 and may play a physiological role for sperm transport.
\end{abstract}

Keywords: electromyography; seminal oestrogens; gilt; uterine contractions; cycle

\section{Introduction}

The pattern of uterine myometrial activity during the cycle is well established in several farm animal species such as the cow (Zerobin \& Spörri, 1972; Ruckebusch \& Bayard, 1975; Rodriguez-Martinez

$\Varangle$ Present address: Institut für Kleintierzucht Celle, POB 280, 3100 Celle, FRG.

\$Present address: Medizinische Hochschule Hannover, Abt. Endokrinologie, POB $61 \quad 01 \quad 80,3000$ Hannover 61, FRG. 
et al., 1987), the sheep (Naaktgeboren et al., 1973; Rousseau \& Prud'homme, 1974; Ruckebusch \& Bueno, 1976; van der Weyden, 1983), and the mare (Taverne et al., 1979a). The characteristic changes of the activity were found to be related to the pattern of circulating concentrations of ovarian steroids.

In the pig a dependency of the in-vitro contractility of the myometrium on the stage of the cycle was reported initially many years ago (Keye, 1923; King, 1927). In-vivo evaluation of uterine activity in conscious sows throughout the cycle, however, has yet to be shown. Also, the influence of ovarian steroids on uterine contractions has not been investigated systematically.

Compared to the spontaneous pattern of contractions on the day of standing reflex (Day 0 ), both the frequency of uterine contractions and the amplitude are increased following natural mating or artificial insemination (AI) (Döcke \& Worch, 1963; Zerobin, 1968; Bower, 1974). This may be explained by mechanical effects of large volumes and cervical stimulation (Zerobin, 1968; Bower, 1974). As semen had a specific effect when compared to the same volumes of saline, a considerable contribution may be ascribed to components of boar semen (Döcke \& Worch, 1963). So far the stimulatory substances are unknown. Boar semen is poor in prostaglandin (PG) F-2 $\alpha$ (Hunter, 1973) and oxytocin (Sander-Richter, 1986), but high concentrations of oestrogens are measurable (Claus et al., 1983, 1985). These steroids might offer an explanation for the increase of contractions after natural mating.

It was the aim of this study to record the electrical activity of the myometrium continuously throughout the cycle and to relate the changes to the concentrations of circulating progesterone and oestradiol. To test the hypothesis of a stimulatory function of seminal oestrogens, a followup study was concerned with the effects of an intrauterine infusion of oestrogens on the uterine electromyographic activity (EMG) during oestrus.

\section{Materials and Methods}

Experimental design. Two sets of experiments were carried out. To monitor the spontaneous patterns of uterine activity and their relationships to the levels of circulating ovarian steroids, the EMG was recorded in 5 gilts continuously for 24 days (Exp. 1). Thus two oestrous periods were available for each of the 5 animals for EMG evaluation.

In Exp. 2 possible effects of seminal oestrogens on uterine contractions were investigated in another 9 gilts on Day 0 (standing oestrus): $10 \mathrm{ml}$ saline $(0 \cdot 15 \mathrm{M}-\mathrm{NaCl})$ with $100 \mu \mathrm{l}$ ethanol or saline with the addition of oestrogens in $100 \mu \mathrm{l}$ ethanol were directly infused into the uterine lumen via intrauterine catheters. The infusion took $5 \mathrm{~min}$, as the flow rate was standardized to $2 \mathrm{ml} / \mathrm{min}$. Controls had infusion catheters, but received no infusion. The amount of oestrogens per treatment was $11.5 \mu \mathrm{g}$ consisting of $5 \mu \mathrm{g}$ oestradiol, $2 \mu \mathrm{g}$ oestrone and $4.5 \mu \mathrm{g}$ oestrone sulphate. These oestrogens and amounts had been measured previously in boar ejaculates (Hoang-Vu, 1987). The EMG was recorded for an 11 -h period. The infusion catheters were rinsed after the first hour with $10 \mathrm{ml}$ saline and treatment was begun $1 \mathrm{~h}$ later. One of the gilts was subject to all 3 treatments in consecutive cycles and 2 of the gilts were used in 2 treatments. Altogether, 4 gilts were evaluated in the saline and saline-oestrogen treatment and 5 controls were included.

Animals and housing. Cyclic German landrace gilts were used for the studies. The weights ranged between 98 and $121 \mathrm{~kg}$ and the mean age was 11 months (range 9-12 months) at the beginning of the experiments. They were housed at the Institut für Tierzucht und Tierverhalten, Mariensee, under a constant light regimen with 12-h light (06:00-18:00 h). They were kept in individual crates before and after surgery when not used for recording. The temperature was $18-20^{\circ} \mathrm{C}$ and the relative humidity $60-80 \%$. The animals were fed a standard diet for non-pregnant sows. Oestrus was checked daily either without a boar (Exp. 1) or twice daily in the presence of a mini-pig boar (Exp. 2). The day of the first occurrence of the standing reflex was designated as Day 0 . Surgery was carried out during the luteal phase. The next oestrus was observed and 4 days before the anticipated next oestrus the gilts were transferred into an environmentally controlled unit (Model 405A: Industrial Acoustics Comp., New York, NY, USA). Since this unit had room for only 2 animals, the gilts entered the experiment consecutively in pairs.

Surgery. After induction of surgical anaesthesia all animals were fitted with indwelling jugular vein catheters (Ellendorff et al., 1977) and implanted with bipolar electrodes, as previously described for the sheep (Naaktgeboren et al., 1973) and the sow (Taverne et al., 1979b). First a bipolar electrode was placed $7 \mathrm{~cm}$ from the end of the cervix on the right uterine horn, then a second electrode was fitted $4 \mathrm{~cm}$ cranial to the first one (see Fig. 1). The cables were protected with a Silastic tube cover and guided subcutaneously from the mid-ventral abdominal area to the flank area where they were exteriorized. In the gilts used in Exp. 2, additionally an infusion catheter was inserted into the corpus 
uteri (see Fig. 1). It consisted of a disc (Silastic sheeting, Dow Corning, Midland, MI, USA: 1.02 mm; diameter $1.5 \mathrm{~cm}$ ) and tubing (o.d. $3.18 \mathrm{~mm}$; i.d. $1.57 \mathrm{~mm}$; length $94 \mathrm{~cm}$ ). The disc was fixed with elastomer $3 \mathrm{~cm}$ distant from the tip of the catheter that was placed into the uterine lumen. Then the disc was sutured to the surface of the uterus. The other end of the catheter was guided to the flank area and exteriorized together with the electrode cables. The catheter was filled with sterile physiological saline $(0.15 \mathrm{M}-\mathrm{NaCl})$ and kept tightly closed when not used for infusion. The application of oestrogens in $10 \mathrm{ml}$ saline through a chronic catheter was necessary as exploratory experiments (transcervical infusion of $100 \mathrm{ml}$ saline) had suggested that mechanical stimulation leads to changes of the EMG, masking a specific effect of oestrogens. Standard post-operative care of the animals consisted routinely of $3 \mathrm{ml}$ Tardomyocel/ $50 \mathrm{~kg}$ i.m. (Bayer Leverkusen, FRG) after operation and $275 \mathrm{mg}$ Reverin i.v. (Hoechst, FRG) on each of the following 4 days. The flank area around the entrance of the cables was kept clean and treated daily with an antibiotic. All gilts remained cyclic.

Electromyograms (EMG). In the environmentally controlled unit the gilts were kept in individual crates. The electrode cables were connected to a physiograph outside the unit (Exp. 1). Since diurnal influences on the myometrial activity could be excluded by the results in Exp. 1, the EMG was recorded in Exp. 2 at Day 0 only from 08:00 until 19:00 h.

The physiograph had a constant paper speed of $0.5 \mathrm{~mm} / \mathrm{sec}$. All signals from both electrodes were filtered, amplified and processed by a selector coupler, a preamplifier (461 D, Beckman) and an amplifier (411 N, Beckman). The high frequency cut-off was $32 \mathrm{~Hz}$ and the time constant $0.03 \mathrm{sec}$. For the recording electrode (Fig. 1:2nd electrode) the sensitivity was set between 50 and $100 \mu \mathrm{V} / \mathrm{mm}$ pen deflection to ensure the evaluation of cyclic changes of the amplitude. Thus amplitudes between 180 and $2200 \mu \mathrm{V}$ could be differentiated. The sensitivity setting was kept constant in both experiments to obtain comparable results. The other electrode (Fig. 1: 1st electrode) was used with a different sensitivity of the amplifier to monitor artefacts due to movements of the animals. Continuous video records of the animals (during the dark phase of Exp. 1: illumination by red light) served to identify further movement artefacts. The records were evaluated by measuring the pen deflection for frequency (contractions/h), duration (sec) and amplitude $(\mu \mathrm{V})$. A contraction occurred if the pen deflection exceeded $180 \mu \mathrm{V}$ and was terminated if the pen deflection ceased for at least $2 \mathrm{sec}$.

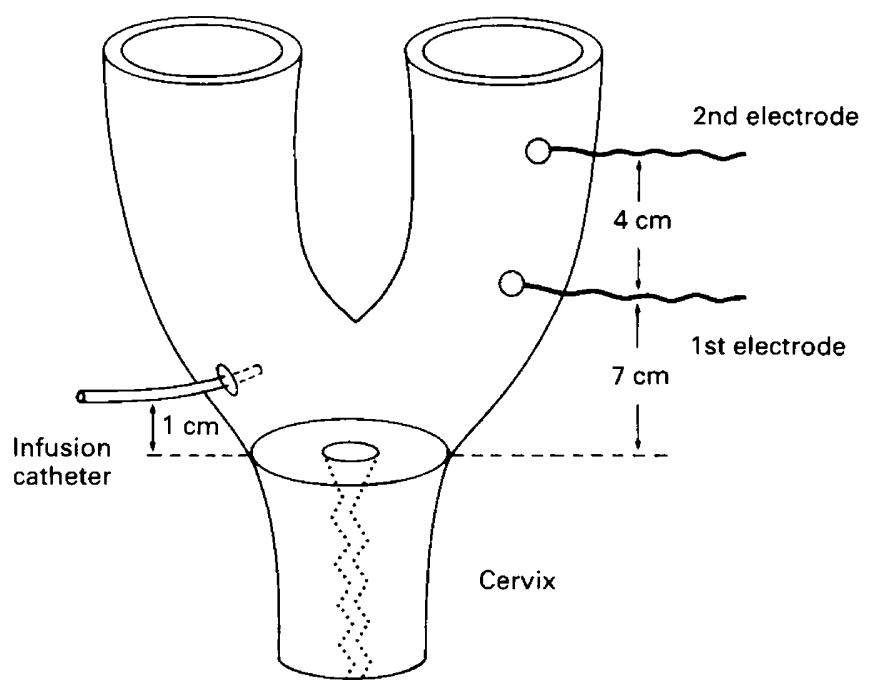

Fig. 1. Position of electrodes on the uterine horn and the infusion catheter in the corpus uteri.

Blood sampling and steroid determination. Blood samples were withdrawn daily $(08: 00 \mathrm{~h})$, collected in heparinized tubes, and centrifuged. The plasma was stored at $-20^{\circ} \mathrm{C}$ until assayed.

Progesterone was measured by a specific radioimmunoassay similar to that used by Parvizi et al. (1976) and Elsaesser (1980). The antiserum had been raised against progesterone-11-hemisuccinate-BSA. The lower limit of sensitivity was $0.2 \mathrm{ng} / \mathrm{ml}$. The precision was determined by measuring known amounts of progesterone added to charcoal-stripped plasma $(0.5$ or $2.5 \mathrm{ng} / \mathrm{ml})$. The measured concentrations were $0.51 \pm 0.01$ and $2.57 \pm 0.11 \mathrm{ng} / \mathrm{ml}$ respectively. Depending on the concentrations used, the intra- and interassay variation coefficients were between 5 and $9 \%$ and 10 and $14 \%$.

Oestradiol was also measured by a specific radioimmunoassay following extraction and lipid separation (Claus et al., 1987a). The antiserum had been raised against oestradiol-6-carboxymethyl-BSA. The lower limit of sensitivity was $4 \mathrm{pg} / \mathrm{ml}$. Measurements in samples known to contain 10 or $50 \mathrm{pg} / \mathrm{ml}$ resulted in values of $12.0 \pm 0.06$ and $58.5 \pm 1 \cdot 1 \mathrm{pg} / \mathrm{ml}$, respectively. The intra- and interassay coefficients of variation were both between $5 \cdot 2$ and $7.5 \%$. 
Statistical evaluation. Mean values including s.e.m. were calculated. To evaluate the relationship between contractions (mean values from the period of 09:00-11:00 h and 14:00-16:00 h) and the steroid levels from samples taken at $08: 00 \mathrm{~h}$ at the same day, the coefficients of correlation and the equations of regression between the concentrations of progesterone or oestradiol and frequency, duration and amplitude of contractions were calculated and the levels of significance were determined (Sachs, 1984).

To evaluate differences between treatments an analysis of variance (ANOVA) was applied. Data were tested for homogeneity by the F-test, differences between groups were tested for significance by Student's $t$ test. Differences within a treatment group were tested for significance by the paired $t$ test (Sachs, 1984).

\section{Results}

\section{Experiment 1: spontaneous activity}

In 2 gilts the hourly means of the frequency, duration and amplitude were calculated for complete 24-h records of each day of the cycle to detect possible diurnal variations. All criteria remained relatively constant for both gilts over any 24 -h period. Large differences, however, were observed in the pattern of contractions between different days. Therefore, in all 5 animals the frequency, duration, and amplitude of the EMG were evaluated daily between 09:00 and 11:00 $\mathrm{h}$ and 14:00 and 16:00 h. Examples of characteristic records of the EMG and the relationship to peripheral steroid concentrations are depicted in Fig. 2 for an individual animal. The EMG includes 10-min periods for every day of the cycle. For the whole cycle the mean values for steroid concentrations and EMG characteristics are summarized in Fig. 3.

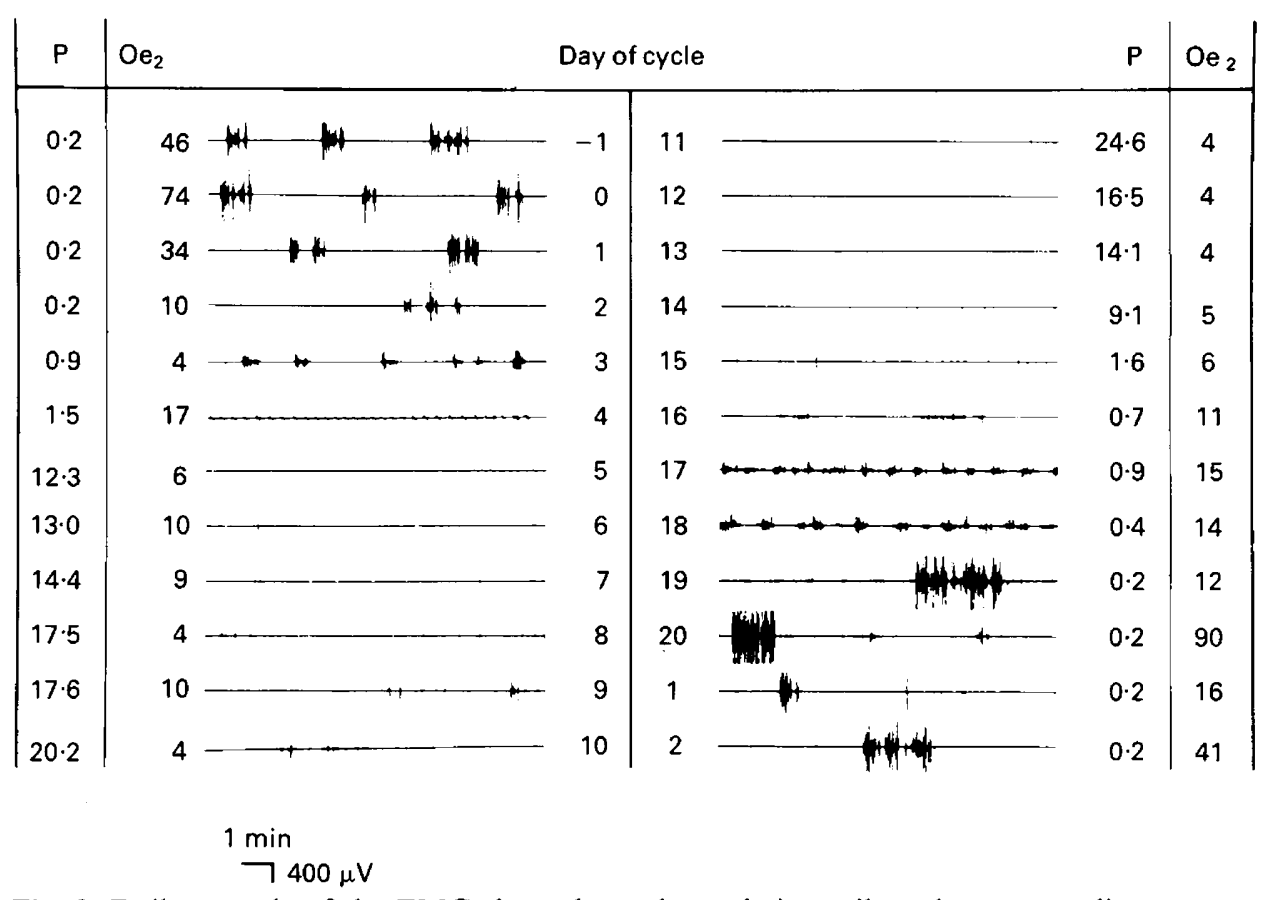

Fig. 2. Daily records of the EMG throughout the cycle in a gilt and corresponding concentrations of progesterone $(\mathrm{P}, \mathrm{ng} / \mathrm{ml})$ and oestradiol $\left(\mathrm{Oe}_{2}, \mathrm{pg} / \mathrm{ml}\right)$ in peripheral blood plasma. Day 0 is the first day of standing heat.

Progesterone and oestradiol concentrations revealed the expected and well established pattern. Lowest concentrations of progesterone $(0.39 \pm 0.13 \mathrm{ng} / \mathrm{ml}, n=10)$ were measured on Day 0 of both oestrous periods. Maximal concentrations during the luteal phase were $22 \cdot 2 \pm 4 \cdot 2 \mathrm{ng} / \mathrm{ml}$ 


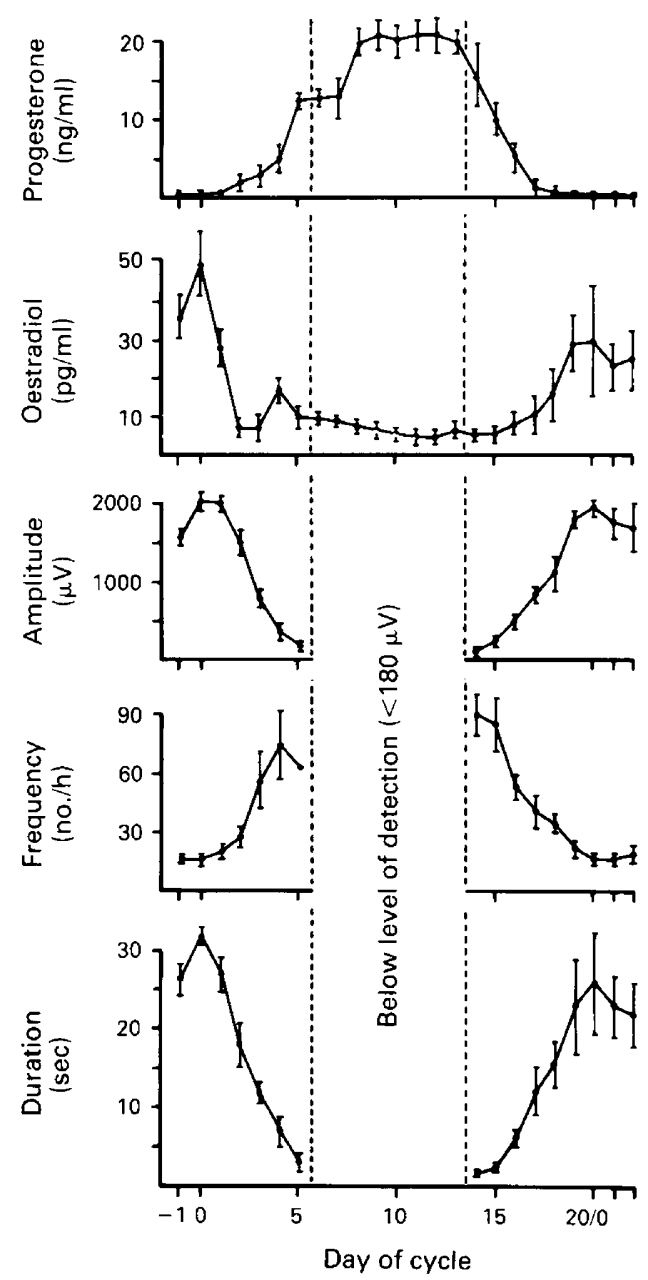

Fig. 3. Electrical myographic activity and steroid concentrations in 5 gilts throughout the cycle.

Values are mean \pm s.e.m.

$(n=5)$. Highest levels of oestradiol generally were found in all animals on Day $0(47.8 \pm 6.7 \mathrm{pg} / \mathrm{ml}$, $n=10$ ). Absolute concentrations on Day 0 ranged from $20 \cdot 4$ to $89.9 \mathrm{pg} / \mathrm{ml}$. After Day 0 oestradiol concentrations dropped and remained below $10 \mathrm{pg} / \mathrm{ml}$ between Days 7 and 16 . The electrical activity revealed continuous changes depending on the stage of cycle and the concomitant hormone pattern. These changes were similar to all 5 animals studied.

On Day 0 the myometrial activity was characterized by its largest amplitude ( 7 cases above $2200 \mu \mathrm{V}, 3$ cases $1800 \mu \mathrm{V})$ and its longest duration $(32.0 \pm 1.7 \mathrm{sec}, n=10)$, but its lowest frequency $(15.8 \pm 2.1$ contractions/h). At 1 day later, when oestradiol values had already dropped significantly $(P<0.05)$ and progesterone was still low, a decrease in the amplitude and the duration along with an increase in the frequency were measurable. The decline in amplitude and duration and the increase in frequency continued until Day 5 . Thereafter the electrical activity was below the detection limit until Day 13. With the onset of luteolysis, indicated by a first drop of progesterone concentrations on Day 14, EMG activity reappeared. It started as high frequent oscillation at a low amplitude and duration. With a further decline of progesterone and a later increase of oestradiol (Day 17), both the amplitude and the duration increased, whereas the frequency decreased. The 
maxima of the amplitude and the duration as well as the minimum of the frequency again coincided with the day of highest oestradiol concentrations (Day 0 ). The correlation coefficients between the myometrial activity and the concentrations of progesterone and oestradiol were highly significant (Table 1). Increasing concentrations of oestradiol and simultaneously decreasing concentrations of progesterone were therefore associated with a rise in the duration and the amplitude of contractions but a decrease in the frequency. During high progesterone concentrations in the luteal phase (Days 6-13), the contractions were below the limit of detection.

Table 1. Coefficients of correlation between steroid concentrations and criteria of the myometrial activity in cyclic gilts ( $n=80$ pairs of values each)

\begin{tabular}{lcrrr}
\hline & Oestradiol & Frequency & Duration & Amplitude \\
\hline Progesterone & $-0.44^{*}$ & $0.52^{*}$ & $-0.60^{*}$ & $-0.55^{*}$ \\
Oestradiol & & $-0.44^{*}$ & $0.63^{*}$ & $0.59^{*}$ \\
Frequency & & & $-0.71^{*}$ & $-0.75^{*}$ \\
Duration & & & $0.78^{*}$ \\
\hline
\end{tabular}

$* P<0 \cdot 001$.

A separate evaluation for oestradiol effects on the EMG was carried out on Day 0 when progesterone concentrations were at their nadir ( 5 animals, 2 oestrous periods each, $n=10$ ). The amplitude exceeded the range of pen deflection $(2200 \mu \mathrm{V})$ on this day on 7 out of 10 occasions. As the pen had to be reset uncalibrated the amplitude was excluded from further evaluation. A significant correlation was found between the concentrations of oestradiol and the duration of contractions $(r=0 \cdot 81, n=10, P<0.01)$ but not the frequency $(r=0 \cdot 16, n=10$, n.s.). The equation of regression between the oestradiol concentrations $(x)$ and the duration $(y)$ was $y=15 \cdot 10+0 \cdot 33 x$.

\section{Experiment 2: oestrogen infusion}

Endogenous concentrations at the day of standing heat were similar in all 3 treatment groups. The concentrations of oestradiol $(\mathrm{pg} / \mathrm{ml}$ ) were $49.0 \pm 7.9$ (controls, $\mathrm{N}=5$ ), $52.0 \pm 8.2$ (saline infused, $N=4$ ), and 54.0 $\pm 7 \cdot 7$ (saline-oestrogen-infused, $N=4$ ). The corresponding progesterone concentrations $(\mathrm{ng} / \mathrm{ml})$ were $0.4 \pm 0.1,0.3 \pm 0.2$ and $0.4 \pm 0.1$ respectively.

The duration and frequency of myometrial contractions for all groups are shown in Fig. 4 . The duration per contraction remained rather constant with about $30 \mathrm{sec}$ in all three groups over the $11-\mathrm{h}$ periods. Irrespective of the constant means the variability between individuals (indicated by s.e.m.), increased with endogenous oestrogen concentrations (see above). In contrast, the frequencies differed remarkably between the treatment groups. The control animals (no infusion or catheter flushing) showed a constant frequency of $15 \cdot 3 \pm 0.2$ contractions/h throughout the period of investigation. In the other 2 groups, flushing of the catheter led to a minor but non-significant increase of the frequency in the order of $2-3$ contractions/h, from $14.0 \pm 3 \cdot 1$ in the salineoestrogen group and $18 \cdot 3 \pm 2 \cdot 2$ in the saline group. The subsequent infusion of saline did not further increase the frequency. Oestrogens in saline specifically increased the frequency of contractions up to a maximum of $31.3 \pm 3.9$ during the 2 nd hour after infusion. The following continuous decrease in the frequency returned to the pretreatment level $7 \mathrm{~h}$ after infusion $(13.8 \pm 2 \cdot 7)$. The increase was significant at Hours $+2(31 \cdot 3 \pm 3.9 / \mathrm{h}, P<0.001),+3(28.8 \pm 2.3 / \mathrm{h}, P<0.001)$ and $+4(21 \cdot 3 \pm 2 \cdot 4 / \mathrm{h}, P<0 \cdot 05)$. The differences between the oestrogen-infused and the control group were significant at the 2 nd $(P<0.05)$ and 3 rd hour after infusion $(P<0.01)$. Also, the contraction frequency in the saline-oestrogen-infused group differed significantly from that in the salineinfused group $(P<0.05)$ from the 2 nd until the 4 th hour. 

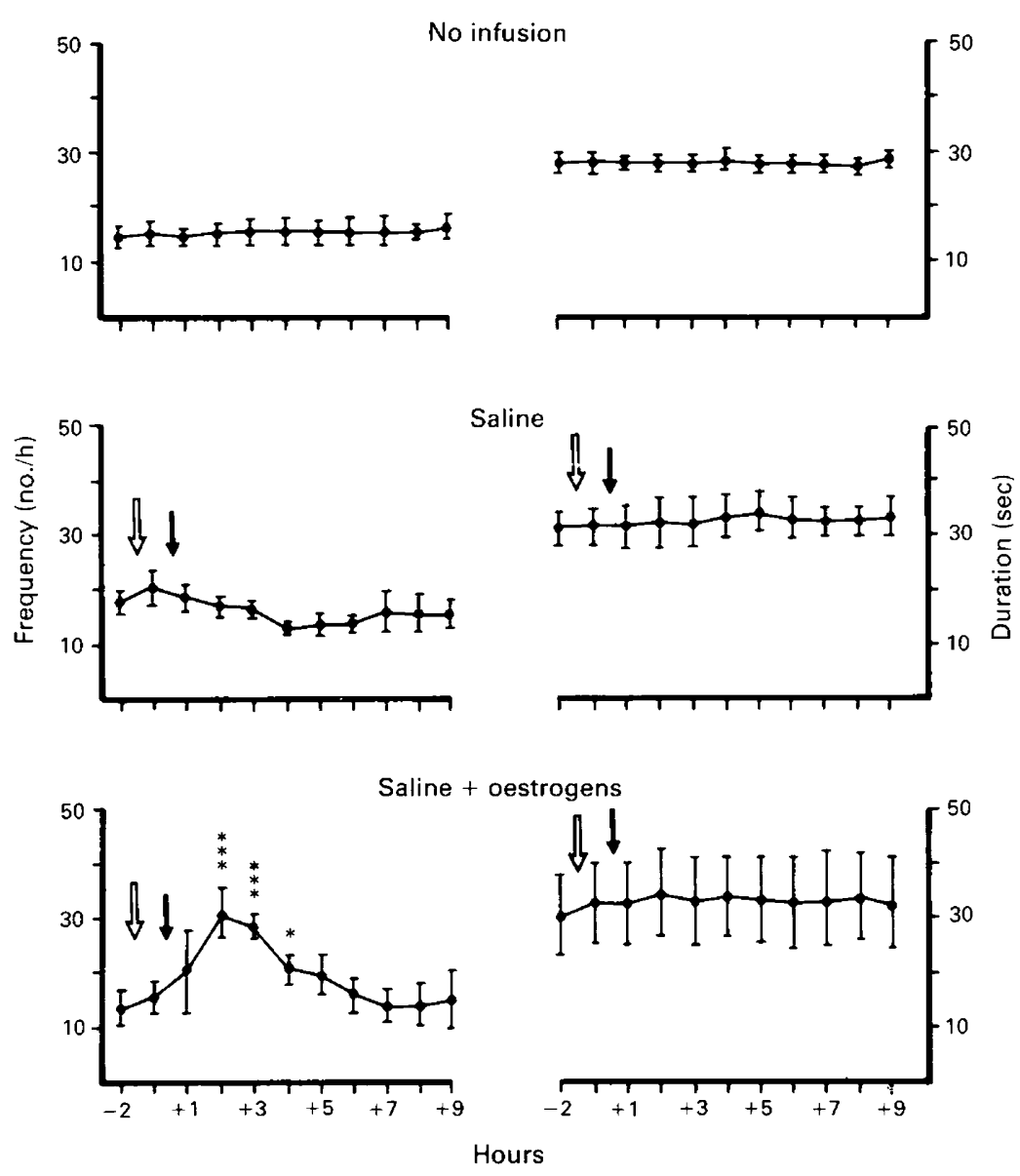

Fig. 4. Frequency and duration of myometrial contractions (mean \pm s.e.m.; hourly periods before and after infusion) in untreated $(N=5)$ gilts and after infusion of saline $(N=4)$ or saline + oestrogens $(\mathrm{N}=4)$. Open arrow: rinsing of infusion catheter; solid arrow: treatment.

\section{Discussion}

Continuous recording of the electrical myometrial activity in 5 pigs throughout the cycle and simultaneous monitoring of the circulating concentrations of ovarian steroids point to a clear interaction between the EMG-pattern and progesterone and oestradiol. A dependency of uterine contractions on ovarian steroids was suggested many years ago (Keye, 1923; King, 1927). Our experiment substantiates for the pig that progesterone is inhibitory and oestradiol is stimulatory to EMG activity. Rising progesterone concentrations after ovulation increased the frequency of contractions. The concomitant decrease in the amplitude and duration of uterine contractions may be related more to the increase of progesterone and less to the decline of oestradiol as shown in Fig. 3. The drop of progesterone during luteolysis $(17.3$ to $5.8 \mathrm{ng} / \mathrm{ml})$ between Days 14 and 16 coincided with an onset and further increase in the duration and amplitude, while at these days oestradiol was still low $(5 \cdot 9-8.5 \mathrm{pg} / \mathrm{ml})$.

Progesterone may therefore inhibit uterine contractility in a concentration-related manner. This is further supported by amplitudes below the detection limit between Days 6 and 13 when progesterone measurements display maximal concentrations. A separate analysis for oestradiol on 
Day 0 , in the absence of progesterone, demonstrated a concentration-related increase in the duration of contractions, whereas the frequency was not significantly affected.

In Exp. 2, however, a specific stimulatory effect of the oestrogen infusions (simulating physiological amounts of seminal oestrogens) on uterine contraction frequency but not the duration was obvious. In controls or the saline-infusion group the contraction frequency was not changed. These contradictory results concerning the effect of oestrogens on the EMG pattern in Exps 1 and 2 may be explained by a role of PGF- $2 \alpha$ as a mediator: oestrogen infusion on Day 0 into the uterus led to a rapid increase of PGF-2 $\alpha$ in the utero-ovarian vein (Claus et al., 1987b). A rise in peripheral concentrations of the metabolite PGFM was measured after oestradiol infusion and mating (Claus et al., 1988). The latter study also shows that prostaglandin concentrations remain elevated for about the same time as increased contraction frequencies were obvious in the present study. In contrast, PGF-2 $\alpha$ and PGFM concentrations are only slightly elevated in untreated sows on Day 0 of the cycle (Gleeson et al., 1974; Shille et al., 1979).

It has been shown that sperm transport to the site of fertilization is dependent on uterine contractions (Hunter, 1973). An appropriate contraction pattern is essential for a high fertilization rate (Viring, 1980, 1981; Hunter, 1982). Therefore, seminal oestrogens may partly explain differences in prolificacy between natural mating and AI (Skjervold, 1975; Le Denmat et al., 1983; Brandt \& Glodek, 1984).

This work was supported by the Deutsche Forschungsgemeinschaft (SPP 'Biologie und Klinik der Reproduktion'). We thank R. Duensing and other members of both Institutes for expert assistance.

\section{References}

Bower, R.E. (1974) Factors affecting myometrial activity in the pig. Ph.D. thesis, University of Minnesota.

Brandt, H. \& Glodek, P. (1984) Der Einfluß der künstlichen Besamung auf die Wurfgröße beim Schwein. Züchtungskunde 56, 27-35.

Claus, R., Schopper, D. \& Wagner, H.-G. (1983) Seasonal effect on steroids in bloodplasma and seminal plasma of boars. J. Steroid Biochem. 19, 725-729.

Claus, R., Schopper, D. \& Hoang-Vu, C. (1985) Contribution of individual compartments of the genital tract to oestrogen and testosterone concentrations in ejaculates of the boar. Acta endocr., Copenh. 109, 281-288.

Claus, R., Hoang-Vu, C., Schopper, D. \& Weiler, U. (1987a) Seasonal variation of the ovarian function in unmated sows revealed by the measurement of progesterone and 17 $\beta$-oestradiol in peripheral bloodplasma. J. vet. Med. A, 34, 344-352.

Claus, R., Hoang-Vu, C., Ellendorfi, F., Meyer, H.D., Schopper, D. \& Weiler, U. (1987b) Seminal oestrogens in the boar: origin and functions in the sow. $J$. Steroid Biochem. 27, 331-335.

Claus, R., Hoang-Vu, C., Ellendorff, F., Meyer, H.D. \& Giménez, T. (1988) Effects of boar seminal oestrogens on uterine contractions and prostaglandin release in the sow. Proc. 1lth Int. Congr. Amin. Reprod. \& AI, Dublin, Vol. 2, Abstr. 17.

Döcke, F. \& Worch, H. (1963) Untersuchungen über die Uterusmotilität und Paarungsreaktionen der Sau. Zuchthygiene 7, 169-178.

Ellendorff, F., Parvizi, N., Elsaesser, F. \& Smidt, D. (1977) The miniature pig as an animal model in endocrine and neuroendocrine studies of reproduction. Lab. Anim. Sci. 27, 822-830.

Elsaesser, F. (1980) Effects of active immunization against oestradiol-17 $\beta$, testosterone or progesterone on receptivity in the female rabbit and evaluation of specificity. J. Reprod. Fert. 58, 213-218.

Gleeson, A.R., Thorburn, G.D. \& Cox, R. (1974) Prostaglandin $F$ concentrations in the utero-ovarian venous plasma of the sow during the late luteal phase of the oestrous cycle. Prostaglandins 5, 512-529.

Hoang-Vu., C. (1987) Elektrische Aktivität des Myometriums beim Schwein während des Zyklus und ihre Beeinflussung durch Infusion von Östrogenen in das Uterusvolumen am Tag der Rausche. Thesis sci. agr., University Hohenheim.

Hunter, R.H.F. (1973) Transport, migration and survival of spermatozoa in the female genital tract: species with intrauterine deposition of semen. In Sperm Transport, Survival and Fertilizing Ability, pp. 309-342. Eds E. S. E. Hafez \& C. Thibault. INSERM, Paris.

Hunter, R.H.F. (1982) Interrelationship between spermatozoa, the female reproductive tract and the egg investment. In Control of Pig Reproduction, pp. 49-63. Eds D. J. A. Cole \& G. R. Foxcroft. Butterworth, London.

Keye, J.D. (1923) Periodic variation in spontaneous contractions in uterine muscle in relation to the oestrus cycle and early pregnancy. John Hopkins Hosp. Bull. $34,60-63$.

King, J.L. (1927) Observation on the activity and working power of the uterine muscle of the non-pregnant sow. Am. J. Physiol. 81, 725-737. 
Le Denmat, M., Dagorn, J. \& Vaudelet, M. (1983) Natural mating and artificial insemination with on farm semen collection. Comparison about prolificacy. Proc. 34th A. Mtg EEAP, Madrid, pp. 750-751.

Naaktgeboren, C., van der Weyden, G.C., Klopper, P.J., Kroon, C.H., Schoof, A.G. \& Taverne, M.A.M. (1973) Electrophysiological observations of uterine motility during the oestrous cycle in sheep. J. Reprod. Fert. 35, $511-518$.

Parvizi, N., Elsaesser, F., Smidt, D. \& Ellendorff, F. (1976) Plasma luteinizing hormone and progesterone in the adult female pig during the oestrous cycle, late pregnancy and lactation and after ovariectomy and pentobarbitone treatment. J. Endocr. 69, 193-203.

Rodriguez-Martinez, H., McKenna, D., Weston, P.G., Whitmore, H.L.A. \& Gustafsson, B.K. (1987) Uterine motility in the cow during the oestrous cycle. I. Spontaneous activity. Theriogenology 27, 337-348.

Rousseau, J.P.A. \& Prud'homme, M.J. (1974) Etude électromyographique de la motricité de l'uterus chez la brebis. Action des hormones. Annls Biol. anim. Biochim. Biophys. 14, 67-85.

Ruckebusch, Y.A. \& Bayard, F. (1975) Motility of the oviduct and uterus of the cow during the oestrous cycle. J. Reprod. Fert. 43, 23-32.

Ruckebusch, Y.A. \& Bueno, L. (1976) An electromyographic study of the uterotubal activity in the ewe. $J$. Reprod. Fert. 47, 221-227.

Sachs, L. (1984) Angewandte Statistik-Anwendung statistischer Methoden. Springer Verlag, Berlin.

Sander-Richter, H. (1986) Untersuchungen zur OxytocinSekretion beim männlichen Schwein. Thesis sci. agr., University Göttingen.
Shille, V.M., Karlbom, I., Einarsson, S., Larsson, K., Kindahl, H. \& Edqvist, L.E. (1979) Concentrations of progesterone and 15-keto-13,14-dihydro-prostaglan$\operatorname{din} \mathbf{F}_{2 \mathrm{a}}$ in peripheral plasma during the estrous cycle and early pregnancy. Zentbl. VetMed. A 26, 169-181.

Skjervold, H. (1975) Comparisons of litter size by use of natural and by artificial mating in pigs. $Z$. Tierzüchtg. Züchtgsbiol. 92, 252-259.

Taverne, M.A.M., van der Weyden, G.C., Fontijne, P., Dieleman, S.J., Pasjen, R.L. \& Allen, W.R. (1979a) In-vivo myometrial electrical activity in the cyclic mare. J. Reprod. Fert. 56, 521-532.

Taverne, M.A.M., Naaktgeboren, C., Elsaesser, F., Forsling, M. L., van der Weyden, G.C., Ellendorf, F. \& Smidt, D. (1979b) Myometrial electrical activity and plasma concentrations of progesterone, estrogens and oxytocin during late pregnancy and parturition in the miniature pig. Biol. Reprod. 21, $1125-1134$

van der Weyden, G.C. (1983) Myometrial activity in the non-pregnant Texel-ewe. Ph.D. thesis, University of Utrecht.

Viring, S. (1980) Distribution of live and dead spermatozoa in the genital tract of gilts and different time after insemination. Acta vet. scand. 21, 587-597.

Viring, S. (1981) Studies on the sperm transport in the genital tract of gilts. Thesis, Swedish University of Agricultural Sciences, Uppsala.

Zerobin, K. (1968) Untersuchungen über die Uterusmotorik des Schweines. Zentbl. VetMed. A 15, 740-798.

Zerobin, K. \& Spörri, H. (1972) Motility of the bovine and porcine uterus and fallopian tube. Adv. Vet. Sci. comp. Med. 16, 303-354.

Received 16 February 1989 